OPEN ACCESS

Edited by:

Neelima Roy Sinha, University of California, Davis,

United States

Reviewed by:

Lee Jeong Hwan,

Jeonbuk National University,

South Korea

Michael Lenhard,

University of Potsdam, Germany

*Correspondence: Jifeng Deng

jifeng-deng@syau.edu.cn

Specialty section:

This article was submitted to Plant Development and EvoDevo,

a section of the journal

Frontiers in Plant Science

Received: 17 March 2020

Accepted: 08 March 2021

Published: 30 March 2021

Citation:

Zhang L, Guo C, LU X, Sun X,

Liu C, Zhou Q and Deng J (2021)

Flower Development

of Heterodichogamous Juglans

mandshurica (Juglandaceae).

Front. Plant Sci. 12:541163.

doi: $10.3389 /$ fp/s.2021.541163

\section{Flower Development of Heterodichogamous Juglans mandshurica (Juglandaceae)}

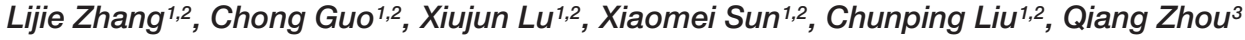 \\ and Jifeng Deng ${ }^{1,2 *}$ \\ ${ }^{1}$ College of Forestry, Shenyang Agricultural University, Shenyang, China, ${ }^{2}$ Key Laboratory of Forest Tree Genetics and \\ Breeding of Liaoning Province, Shenyang, China, ${ }^{3}$ Liaoning Forestry and Grassland Administration, Shenyang, China
}

Juglans mandshurica is a monoecious heterodichogamous species with protogynous and protandrous mating strategies that occur at a 1:1 ratio and are randomly distributed in the population. The inconsistent male and female flowering periods of the same mating type result in an imbalance of the ratio of male and female flowers, contributing to the low yield of this species. However, little more is known about its floral development. Following three consecutive years of observations, histological analysis, and scanning electron microscopy, we found that the morphological and anatomical development of the male and female flowers were synchronous. The male floral morphological development of $\mathrm{J}$. mandshurica was divided into seven phases, while that of the female flower was nine. Four stages were shared between the male and female flower's anatomical development. Our findings indicate that there was minimal overlap between sexual functions within the same mating type, guaranteeing synchronization, mutual non-interference, outcrossing, and avoidance of self-fertilization. These results provide a theoretical basis for the improvement of fruit yield and quality through the reasonable allocation of protogynous and protandrous individuals in a population, and for artificial pollination control. Further, these findings lay a foundation for further research on the genetic mechanisms and environmental effects on flower development of heterodichogamous J. mandshurica.

Keywords: reproductive development, protandry, protogyny, heterodichogamy, Juglans mandshurica maxim

\section{INTRODUCTION}

Heterodichogamy is a transitional mating type between hermaphroditic and dioecious plants (Bai et al., 2006) that contains two mating types, protogynous (female function before male) and protandrous (male function before female) (Endress and Lorence, 2004; Stahl et al., 2019). These two mating types can co-occur within one population, and the ratio of the two types is nearly always 1:1 (Teichert et al., 2011; Wang et al., 2012; Fukuhara and Tokumaru, 2014; Renner, 2014). Heterodichogamous plants include species of Acer (Field and Barrett, 2012), Alpinia (Li et al., 2001), Carya (McCarthy and Quinn, 1992), Corylus (Muller, 1875), Grayia (Pendleton et al., 1988), Hernandia (Endress and Lorence, 2004), Persea americana (Stahl et al., 2019), and Juglans (Kimura et al., 2003). Notably, although some Acer species have bisexual flowers, the flowers are functionally unisexual or monoecious (Jacobs and Lersten, 1994).

Monoecious plant species have separate male and female flowers on the same plants and can therefore undergo self-fertilization when the pollen of staminate flowers contacts the stigma of 
pistillate flowers, barring other defenses against selfing (Mao et al., 2017; Avalos et al., 2019; Hildesheim et al., 2019). Heterodichogamy, which is dispersed and reported in 20 genera from 13 families of flowering plants, is one of the evolutionary pathways from monoecy to dioecy, heterodichogamous populations usually contain two sexual morphs, protogynous and protandrous, which are reciprocal (Meng et al., 2009; Liu et al., 2016). Hermaphroditism brings about the risk of pollination interference, pollen wastage, etc., but does not prevent it. Other mechanisms like heterodichogamy have evolved to prevent these effects (Ye et al., 2019). Juglans mandshurica Maxim (J. mandshurica) is a monoecious heterodichogamous species also referred to as Carya cathayensis and commonly known as hickory. J. mandshurica is one of the "three hardwood and broad-leaved tree species" (along with Fraxinus mandshurica and Phellodendron amurense) known to occur in the Xiaoxinganling Mountains, Wanda Mountains, Changbai Mountains, the eastern mountainous areas of Liaoning province, China; it has also been documented in Russia's Far East, in North Korea, and in Japan (Wang et al., 2008; Zhao and Woeste, 2011; Zhang et al., 2012; Zhao et al., 2014; Hu et al., 2016; Jin et al., 2016). J. mandshurica is a tertiary relict species and is a national class II and class III protected rare plant and endangered tree species in China (Chen et al., 2014). J. mandshurica is an economically important woody plant (Ros and Mataix, 2006; Hasan et al., 2011; Salimi et al., 2012; Vinson and Cai, 2012; Zhao et al., 2014), but existing J. mandshurica resources are distributed primarily in natural forests, which are under threat due to excessive logging and imbalances in harvesting and breeding (Guo et al., 2015). At present, yields of J. mandshurica walnut fruit are in sharp decline, and timber yields account for less than $1 \%$ of the total timber output of the eastern mountainous areas of Liaoning, China. The developmental asynchronization of flowers in protogynous and protandrous mating types in J. mandshurica could prevent selfing and increase the probability of outcrossing, but could also result in an imbalance in the ratio of male and female flowers, thereby affecting yields. Although J. mandshurica has been extensively studied, research has thus far primarily focused on its pharmacological properties (Carvalho et al., 2010; Sharma et al., 2013; Xu et al., 2013) and population dynamics (Wang et al., 2015). Few reports have studied the reproductive biology of heterodichogamous J. mandshurica in Eastern Liaoning Province, China, where J. mandshurica naturally occurs in the greatest density. Therefore, in the present study, the morphology and anatomical structure of flowers at each phenological growth stage were observed and investigated continuously. This research could provide a scientific basis for further studies on the molecular regulatory mechanisms governing flower development in heterodichogamous plants.

\section{MATERIALS AND METHODS}

\section{Tree Species}

Juglans mandshurica is a monoecious and deciduous species of tree that is predominantly wind-pollinated. The tree reaches heights of $20 \mathrm{~m}$ with extended branches, an oblate crown shape, and gray bark (Bai et al., 2006). J. mandshurica commences flowering in early spring. The young shoot is covered with short hairs. Odd-pinnate leaves on sprouts can reach up to $80 \mathrm{~cm}$, and the petiole is $9-14 \mathrm{~cm}$ long, with $15-23$ leaflets of 6-17 cm long and $2-7 \mathrm{~cm}$ wide. The staminate inflorescences are pendulous catkins 9-20 cm in length with 4-10 male flowers per catkin. The flowers have 12 stamens, and the anthers are about $1 \mathrm{~mm}$ long. The pistillate inflorescences are vertical spikelets $3-5 \mathrm{~cm}$ in length with 10-18 flowers. The gynoecium has a single ovule and two feathery stigmas (Figure 1).

\section{Study Site and Plant Material Selection}

The study was conducted in the Dichegou experimental forest farm (longitude $12420^{\prime} 06^{\prime \prime}-12528^{\prime} 58^{\prime \prime}$ E, latitude $4147^{\prime} 52^{\prime \prime}$ $4228^{\prime} 25^{\prime \prime} \mathrm{N}$ ), which is located in Wandianzi town, QingYuan Manchu Autonomous County, Fushun City, Liaoning Province, China. The area has a mid-temperate continental monsoon climate, with cold and dry winters, hot and rainy summers, an annual average temperature of $6.6^{\circ} \mathrm{C}$, an annual accumulated temperature of $2,700-3,200^{\circ} \mathrm{C}$, and a frost-free period of 120 125 days. A total of $200 \mathrm{~J}$. mandshurica sample trees (100 protogynous and 100 protandrous) were selected at the study site, and the dates of onset and termination of male and female flowering were recorded for each individual tree from 2017 to 2019. The periods of male and female flowering were determined as described by Bai et al. (2006).

\section{Histological Analysis}

Male and female flower buds were sampled every 3 days from March to June of 2019 (in accordance with tree sap flow activities). The samples were vacuum filtered with FAA fixative for $1 \mathrm{~h}$, and dehydrated sequentially with $50,70,85,95$, and $100 \%$ ethanol alcohol for $2 \mathrm{~h}$ each at room temperature. The samples were then transferred to a mixed solution of 1:1 xylene and anhydrous alcohol for $1 \mathrm{~h}$, after which $20 \mathrm{~mL}$ of pure xylene was added for approximately $2 \mathrm{~h}$ to make the samples visible. The samples were then placed in a mixed solution of ethanol and xylene at ratios of 1:3,1:1, and 3:1 ethanol: xylene for $1 \mathrm{~h}$ each. This process was carried out in a Thermal Chamber (Lisun Electronics Co., Ltd., Shanghai, China) at $3^{\circ} \mathrm{C}$ above the melting point of paraffin wax (approximately $40^{\circ} \mathrm{C}$ ). The samples were subsequently placed in dissolved pure paraffin wax for $30 \mathrm{~min}$, and the process was repeated three times. Paraffin fixing and section slicing were performed using a Leica CM1850 V2.0 (Leica, Germany). The thickness of the wax slices was approximately $8 \mu \mathrm{m}$. Sections were double-stained according to Sass's method (Ruzin, 1999). The sections were sequentially placed into the xylene I, xylene II, anhydrous ethanol I, anhydrous ethanol II, 95\% alcohol, 90\% alcohol, 80\% alcohol, and 70\% alcohol for 20, $20,10,10,5,5,5$, and $5 \mathrm{~min}$, respectively, and were washed with distilled water after being thoroughly dried. The sections were then placed into a $1 \%$ safranine dye solution and dyed for 1-2 h. Tap water was used to remove any excess dye solution. Next, 50, 70, and $80 \%$ alcohol was added to the sections for $3 \mathrm{~min}$ each for decoloration, following which the sections were dyed in $0.5 \%$ solid green dye solution for 30-60 s. Decoloration was carried out in anhydrous ethanol I for $30 \mathrm{~s}$ and anhydrous 


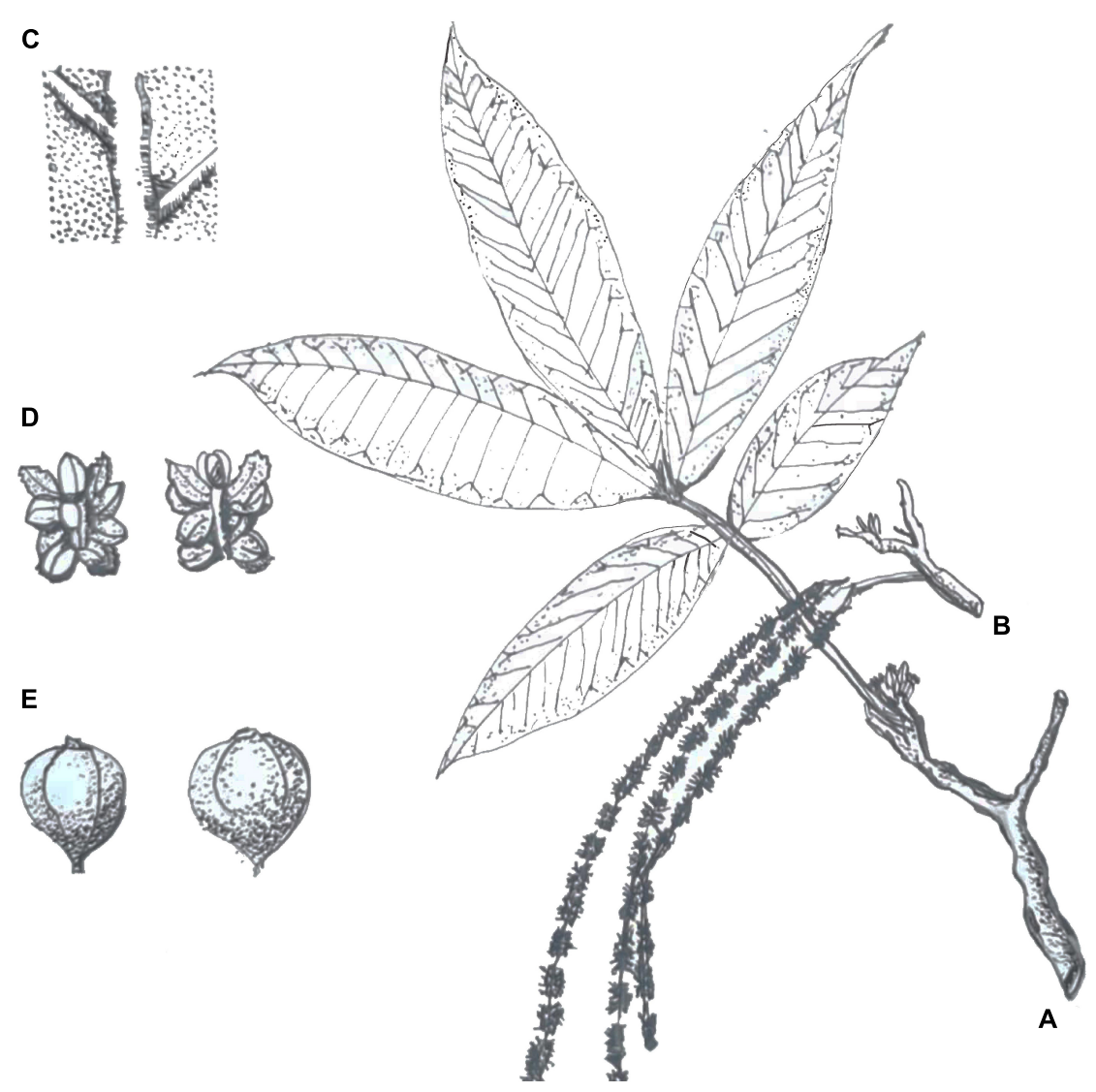

FIGURE 1 | Botanical sketches of Juglans mandshurica Maxim. Panel (A) shows the strip (e.g., spikelets and leaves), panel (B) shows catkins, panel (C) shows the abaxial surface of the leaf, panel (D) shows a staminate flower, and panel (E) shows the fruit (redrew from the artist: Taili Zhang, born in Jin Zhou, China 1938).

ethanol II for $1 \mathrm{~min}$. Finally, the sections were dried in an oven at $60^{\circ} \mathrm{C}$ and placed in xylene solution at ratios of 1:3 ethanol: xylenef for $5 \mathrm{~min}$. The sections were sealed with Canada balsam and photographed under SZX10 stereo and BX53 microscopes (Olympus, Japan).

\section{Scanning Electron Microscopy}

All of the sampled buds were dissected by removing their scales and leaves and fixed with 4 glutaraldehyde for $12 \mathrm{~h}$, rinsed with $0.1 \mathrm{molL}^{-1}$ of phosphoric acid buffer for $1 \mathrm{~h}$, dehydrated with $30,50,70,85$, and $90 \%$ ethanol alcohol for $15 \mathrm{~min}$ each, and dehydrated with $100 \%$ absolute ethyl alcohol for $30 \mathrm{~min}$. After freeze-drying, the materials were critical-point dried using liquid $\mathrm{CO}_{2}$ (Emitech K850, United Kingdom). Samples were placed on a display board and glued. The treated materials were sputtercoated with gold (Hitachi E-1010, Japan) and then observed using an S4800 scanning electron microscope (Hitachi, Japan).

\section{RESULTS}

\section{Flowering Phenology}

The morphological development of male J. mandshurica flowers was divided into seven phases, while the female flower development was divided into nine phases (Figure 2). The male flower buds displayed rust yellow coloration and pilose surfaces with 5-7 mm long hairs. The catkins were 9-20 cm long with a pilose axis. The male flowers had short floral shoots and two bracteoles subtending the petal. The anthers turned from green (immature) to black (after dehiscence), and finally fell off of the shoots. The female bud surface was pilose with 9$15 \mathrm{~mm}$ hairs, and the bud body was brown. In the early stages of development, it was difficult to distinguish the female floral bud from the leaf bud until the air temperature gradually rose and the buds broke, revealing odd-pinnate leaves. Before stage 4 (opening of the bifid stigma to form inverted splayed petaloids), there was no obvious morphological difference between the female flower buds in protogynous and protandrous types, except for the flowering time. At stage 5, such differences became more obvious due to color. The protandrous male flower development lasted approximately 25 days (the starting time was DOY 115, when the sap flow begins, inflorescences started to flower after 1-year development, and new shoots were generated, this time refers to day 0), while the protogynous male flower development lasted approximately 31 days. The female flower development of the protogynous type lasted approximately 37 days, while the protandrous female flower development lasted approximately 45 days. 


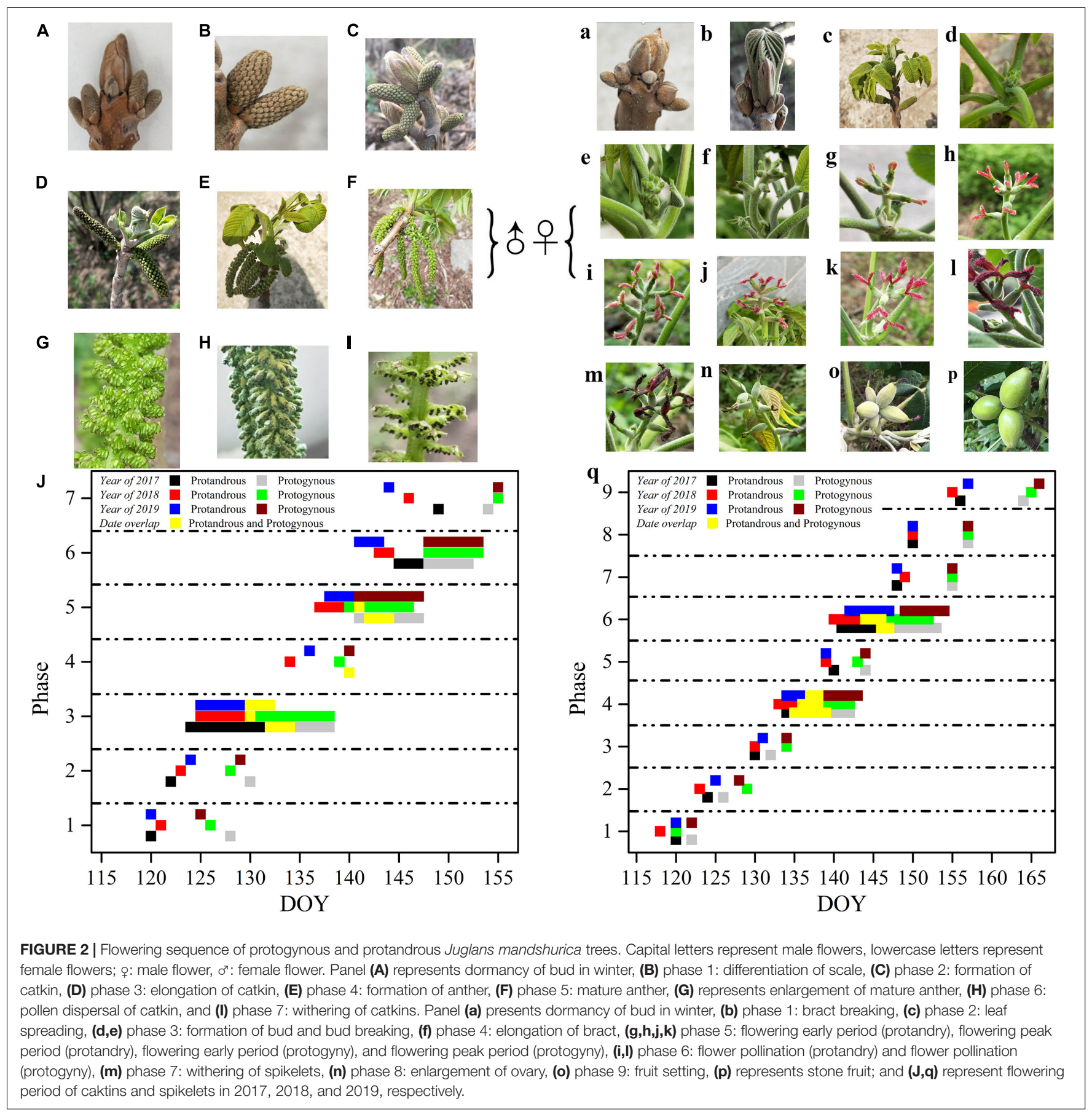

\section{Flower Development Stages}

In order to further understand the developmental characteristics of male and female flowers, flower development was then divided into several stages by key morphological events and developmental order of flower organs with the results of the histocytological changes (Figure 3). In both mating types, the development of both the male and female flowers of J. mandshurica was divided into four stages. For male flowers, the stages included the initial differentiation of the male flower bud (related to phase 1), formation and development of stamen primordia, formation and development of catkins (related to phases 2 and 3), and the formation of anthers and pollen grains (related to phases 4 and 5); for female flowers, stages included initial differentiation of the female flower bud (related to phase 3), formation and development of pistil primordia, formation and development of bract and sepal primordia (related to phase 4), and formation and development of ovule primordia (related to phase 5). The differentiation and development of the male flowers of protandrous trees was earlier than that of protogynous trees, while the differentiation of male flowers of protogynous 
A

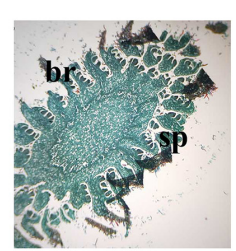

D

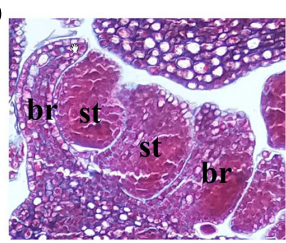

G

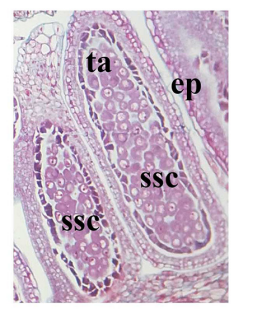

a

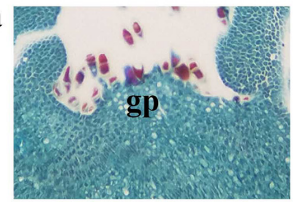

d

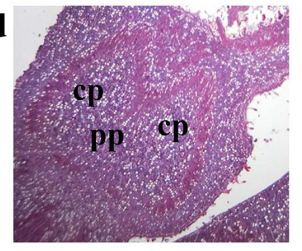

B

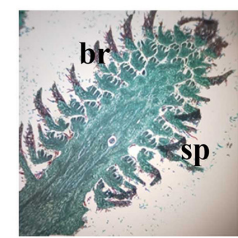

E

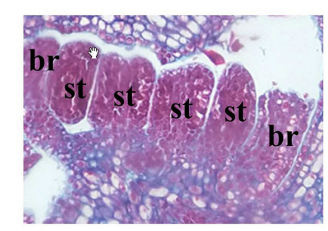

H

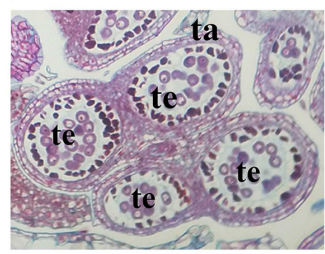

b

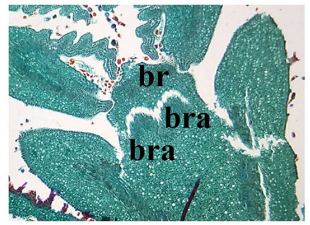

e

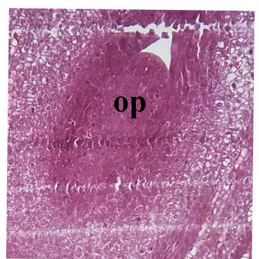

C

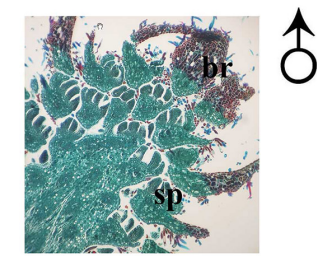

F
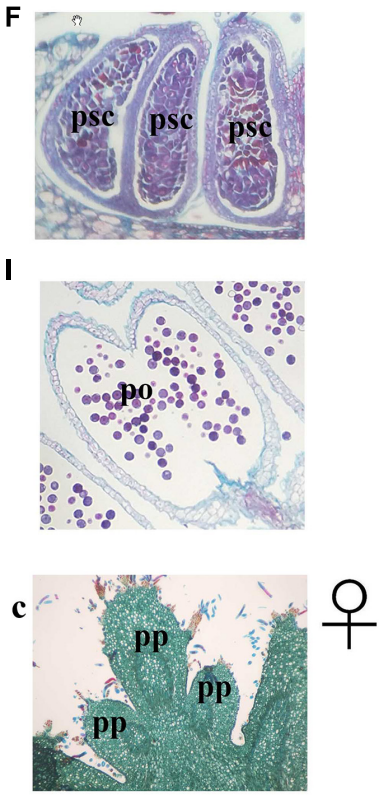

f

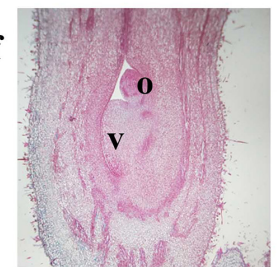

FIGURE 3 | Sections of flower bud tissue from protogynous and protandrous Juglans mandshurica trees. Panel (A) presents initial differentiation of floral bud, panel (B) presents initial formation of stamen, panel (C) presents catkins, panel (D) presents initial formation of anthers, panel (E) presents primary sporogenous cell, panel (F) presents secondary sporogenous cell, panel (G) presents internal structure of anther, panel (H) presents pollen sac, panel (I) presents pollen grain. Panel (a) presents initial differentiation of floral bud, panel (b) presents differentiation of inflorescence primordia, panel (c) presents involucral primordia, panel (d) presents initial formation of primordial ovule, panel (e) presents primordial ovule, and panel (f) presents formation of ovule and ovary. an: immature anther; br, bract; bra, bracteoles; cp, carpellary primordia; ep, epidermal layer; fa, anther after disperse pollen; gp, growth cone; ma, mature anther; o, ovule; op, ovule primordia; po, pollen; pp, pistil primordia; psc, primary sporogenous cell; s, stamen; sp, stamen primordium; ssc, secondary sporogenous cell; ta, tapetum; and v, ovary.

trees was about 3-5 days later than that of protandrous trees. The paraffin section micrographs could reflect the different flower development stages well.

To probe flower buds of $J$. mandshurica into more visible way. Scanning electron micrographs were taken and threedimensional images were obtained. Stamen primordia can be seen inside the dormant buds in winter (Figure 4A). The bract primordia started to grow and it can be seen on the outer edge of the stamen primordia (Figure 4B) and catkins began to elongate, and individual stamens then appeared (Figure 4C). At this time, the anther gradually formed (Figure 4D). When anthers became mature, they broke and dispersed the pollen (Figure 4E) until gradually withering (Figure 4F). Bud primordia were clearly seen during winter dormancy (Figure 4a). The bud primordia were flattened, expanded, and raised in three locations directly after germination of the bud (Figure $\mathbf{4 b}$ ). The middle spot developed into a primordial ovule, and the other two spots became petals (Figure 4f). Figure 4c presents the pistil primordium; its upper part developed into a stigma (Figure 4d), while its lower part developed into an ovary, which surrounded the ovule and then expanded (Figure 4e), completing the fertilization process.

\section{DISCUSSION}

Most species of tree in the genus Juglans are self-pollinated, but our findings strongly indicate that J. mandshurica crosspollinates, a finding consistent with the flowering phenological 


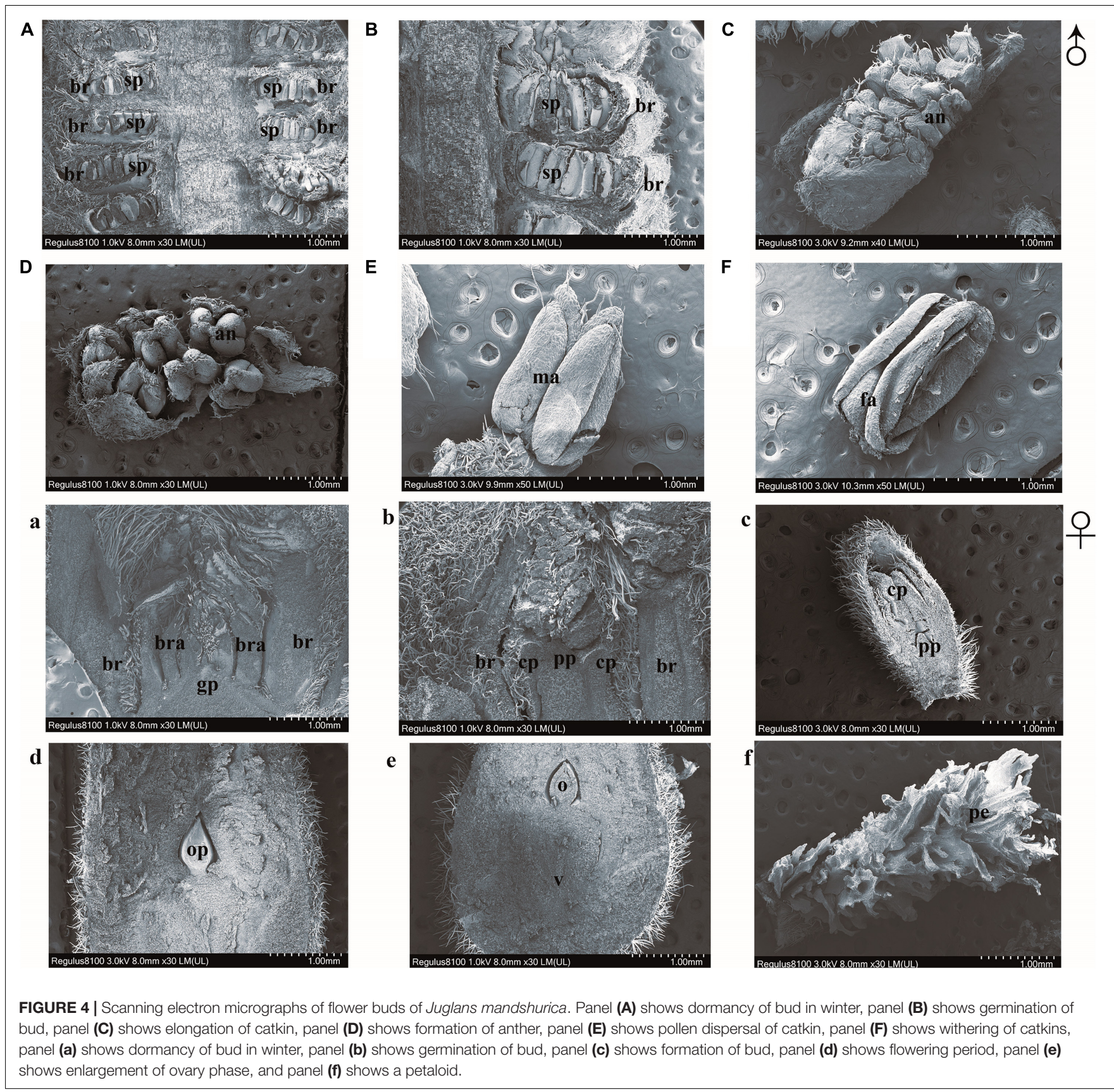

characteristics of J. mandshurica reported by Bai et al. (2007). In addition, research conducted on J. mandshurica indicated that the sexual functions of the two mating types were synchronous and reciprocal within a given population. Therefore, heterodichogamy in J. mandshurica may represent an effective strategy for reducing self-pollination, but if the strategy could increase the pollination efficacy, pollen supplementation and fruit production needed to be tested in the future. However, some studies have shown that outcrossing may shorten the life span of flowers as compared to selfing (Devlin and Stephenson, 1984; Richardson and Stephenson, 1989; Gregg, 1991; Aizen, 1993). Further research building upon the results of the current work will aid in confirming the efficacy of heterodichogamy and outcrossing as reproductive strategies in J. mandshurica.

Adverse climatic conditions at the time of flowering severely hinder yields and may lead to the failure of flower development (Borghi et al., 2019). Nowadays, decline of forests has accelerated in recent decades at the regional and continental scales, as air temperature is continuously rising and models predict a sharp decline in the strength of the terrestrial carbon sink in the next century (Adams et al., 2013). Even if precipitation remains same to the historical levels, continuous warmingassociated extremes raise the possibilities of dieback affecting the metabolism and indirect effects on the flower physiological 
responses, flower metabolic responses, and flowering stages (McDowell et al., 2013). While, to make clear of mechanism of flowering of plants may be dramatic and difficult to predict than is currently assumed, because of the numerous contributing factors (Anderson et al., 2012). Especially in northern China, where human activities and natural hazards like deforestation, over-cultivation, urbanization, wildland fire, has resulted in the degradation of these regions and further threatened the J. mandshurica tree species (Liu et al., 2016). Therefore, more detailed work should focus on the expression of genes associated with known pathways in response to warming and drying trends, downstream signaling from environmental stress responses and flower development and other mechanisms explaining the floral development of male and female flowers in J. mandshurica individually, locally, and regionally, which can toward a common understanding of these processes to the benefit of ecology and society.

\section{CONCLUSION}

The pattern of flower phenology was observed and thoroughly investigated in 200 individuals J. mandshurica trees during 20172019. Minimal overlap was observed between the two sexual functions within individual trees, and the flowering periods of protogynous and protandrous mating types were reciprocal and synchronous, thus promoting outcrossing. The distinctive developmental stages of the male and female floral morphology were classified and revealed in detail.

\section{REFERENCES}

Adams, H. D., Germino, M. J., Breshears, D., Barron-Gafford, G. A., GuardiolaClaramonte, M., Zou, C. B., et al. (2013). Nonstructural leaf carbohydrate dynamics of Pinus edulis during drought-induced tree mortality reveal role for carbon metabolism in mortality mechanism. New Phytol. 197, 1142-1151. doi: $10.1111 / \mathrm{nph} .12102$

Aizen, M. A. (1993). Self-pollination shortens flower lifespan in Portulaca umbraticola HBK (Portulacaceae). Int. J. Plant Sci. 154, 412-415. doi: 10.1086/ 297123

Anderson, J. T., Panetta, A. M., and Mitchell-Olds, T. (2012). Evolutionary and ecological responses to anthropogenic climate change: update on anthropogenic climate change. Plant Physiol. 160, 1728-1740. doi: 10.1104/pp. 112.206219

Avalos, A. A., Zini, L. M., Ferrucci, M. S., and Lattar, E. C. (2019). Anther and gynoecium structure and development of male and female gametophytes of Koelreuteria elegans subsp. formosana (Sapindaceae): phylogenetic implications. Flora 255, 98-109. doi: 10.1016/j.flora.2019. 04.003

Bai, W. N., Zeng, Y. F., and Zhang, D. Y. (2007). Mating patterns and pollen dispersal in a heterodichogamous tree, Juglans mandshurica (Juglandaceae). New Phytol. 176, 699-707. doi: 10.1111/j.1469-8137.2007.02202.x

Bai, W. N., Zeng, Y. F., Liao, W. J., and Zhang, D. Y. (2006). Flowering phenology and wind-pollination efficacy of heterodichogamous Juglans mandshurica (Juglandaceae). Ann. Bot. 98, 397-402. doi: 10.1093/aob/mcl111

Borghi, M., Souza, L. P. D., Yoshida, T., and Fernie, A. R. (2019). Flowers and climate change: a metabolic perspective. New Phytol. 224, 1425-1441. doi: 10.1111/nph.16031

Carvalho, M., Ferreira, P. L., Mendes, V. S., Silva, R., Pereira, J., and Jerónimo, C. (2010). Human cancer cell antiproliferative and antioxidant activities of Juglans regia L. Food Chem. Toxicol. 48, 441-447. doi: 10.1016/j.fct.2009.10.043

\section{DATA AVAILABILITY STATEMENT}

The original contributions presented in the study are included in the article/supplementary material, further inquiries can be directed to the corresponding author.

\section{AUTHOR CONTRIBUTIONS}

All authors commented on the manuscript at all stages. JD and LZ conceived and designed the study. CG, XL, XS, CL, QZ, JD, and $\mathrm{LZ}$ contributed the materials and analysis tools and contributed to the data analysis and manuscript preparation.

\section{FUNDING}

This work was supported by funds from the National Key Research and Development Plan of China (2017YFD0600600), the Foundation for State Major Research Project of China (2017YFD0600605), and the National Natural Science Foundation of China (31800609).

\section{ACKNOWLEDGMENTS}

The authors are very grateful for the support and help of the forest farms in the survey area.

Chen, G. P., Cheng, S. S., Cong, M. Y., Liu, J., Gao, X., Wang, H., et al. (2014). Effects of litter decomposition on soil nutrients in three broad-leaved forests. Chin. J. Ecol. 33, 874-879.

Devlin, B., and Stephenson, A. G. (1984). Factors that influence the duration of the staminate and pistillate phases of Lobelia cardinalis flowers. Bot. Gaz. 145, 323-328. doi: $10.1086 / 337462$

Endress, P. K., and Lorence, D. H. (2004). Heterodichogamy of a novel type in Hernandia (Hernandiaceae) and its structural basis. Int. J. Plant Sci. 165, 753-763. doi: 10.1086/422049

Field, D. L., and Barrett, S. C. H. (2012). Disassortative mating and the maintenance of sexual polymorphism in painted maple. Mol. Ecol. 21, 3640-3643. doi: 10.1111/j.1365-294x.2012.05643.x

Fukuhara, T., and Tokumaru, S. (2014). Inflorescence dimorphism, heterodichogamy and thrips pollination in Platycarya strobilacea (Juglandaceae). Ann. Bot. 113, 467-476. doi: 10.1093/aob/mct278

Gregg, K. B. (1991). Reproductive strategy of cleistes divaricata (Orchidaceae). Am. J. Bot. 78, 350-360. doi: 10.2307/2444957

Guo, L. N., Zhang, R., Guo, X.-Y., Cui, T., Dong, W., and Huo, J.-H. (2015). Identification of new naphthalenones from Juglans mandshurica and evaluation of their anticancer activities. Chin. J. Nat. Med. 13, 707-710. doi: 10.1016/s18755364(15)30070-4

Hasan, T. N., Grace, B. L., Shaf, G., Hazzani, A. A., and Alshatwi, A. A. (2011) Anti-proliferative efects of organic extracts from root bark of Juglans regia L. (RBJR) on MDA-MB-231 human breast cancer cells: role of Bcl-2/Bax, caspases and Tp53. Asian Pac. J. Cancer Prev. 12, 525-530.

Hildesheim, L. S., Opedal, ØH., Armbruster, W. S., and Pélabon, H. (2019). Fitness costs of delayed pollination in a mixed-mating plant. Ann. Bot. 124, 869-881. doi: 10.1093/aob/mcz141

Hu, Z., Zhang, T., Gao, X. X., Wang, Y., Zhang, Q., Zhou, H. J., et al. (2016). De novo assembly and characterization of the leaf, bud, and fruit transcriptome from the vulnerable tree Juglans mandshurica for the development of 20 new 
microsatellite markers using illumina sequencing. Mol. Genet. Genom. 291, 849-862. doi: 10.1007/s00438-015-1147-y

Jacobs, C. A., and Lersten, N. R. (1994). Microsporogenesis and endothecial wall patterns in black maple (Acer saccharum subsp. nigrum, Aceraceae). Bull. Torrey Bot. Club 121, 180-187. doi: 10.2307/2997170

Jin, M., Sun, J., Li, R., Diao, S., Zhang, C., Cui, J., et al. (2016). Two new quinones from the roots of Juglans mandshurica. Arch. Pharm. Res. 39, 1237-1241. doi: 10.1007/s12272-016-0781-1

Kimura, M., Seiwa, K., Suyama, Y., and Ueno, N. (2003). Flowering system of heterodichogamous Juglans ailanthifolia. Plant Spec. Biol. 18, 75-84. doi: 10. 1111/j.1442-1984.2003.00088.x

Li, Q. J., Xu, Z. F., Kress, W., Xia, Y. M., Zhang, L., Deng, X. B., et al. (2001). Flexible style that encourages outcrossing. Nature 410:432. doi: 10.1038/35068635

Liu, J. J., Mao, X., Li, X. C., and Fu, X. X. (2016). A review on flowering mechanism in heterodichogamous plants. J. Nanjing For. Univ. 40, 147-154.

Mao, Y., Liu, W., Chen, X., Xu, Y., Lu, W., Hou, J., et al. (2017). Flower development and sex determination between male and female flowers in Vernicia fordii. Front. Plant Sci. 8:1291.

McCarthy, B. C., and Quinn, J. A. (1992). Fruit maturation patterns of Carya spp. (Juglandaceae): an intra-crown analysis of growth and reproduction. Oecologia 91, 30-38. doi: 10.1007/bf00317237

McDowell, N. G., Ryan, M. G., Zeppel, M. J. B., and Tissue, D. T. (2013). Improving our knowledge of drought-induced forest mortality through experiments, observations, and modeling. New Phytol. 200, 289-293. doi: 10.1111/nph.12502

Meng, Y., Wang, X. H., and Wang, C. H. (2009). Embryology of Juglans mandshurica Maxim. (I) the microsporogenesis, and the development of male gametophytes. Bull. Bot. Res. 29, 681-684.

Muller, H. (1875). Flowering of the hazel. Nature 12:26. doi: 10.1038/012026a0

Pendleton, R. L., McArthur, E. D., Freeman, D. C., and Blauer, A. C. (1988). Heterodichogamy in Grayia brandegei (Chenopodiaceae): report from a new family. Am. J. Bot. 75, 267-274. doi: 10.1002/j.1537-2197.1988.tb13438.x

Renner, S. S. (2014). The relative and absolute frequencies of angiosperm sexual systems: dioecy, monoecy, gynodioecy, and an updated online database. Am. J. Bot. 101, 1588-1596. doi: 10.3732/ajb.1400196

Richardson, T. E., and Stephenson, A. G. (1989). Pollen removal and pollen deposition affect the duration of the staminate and pistillate phases in Campanula rapunculoides. Am. J. Bot. 76, 532-538. doi: 10.1002/j.1537-2197. 1989.tb11344.x

Ros, E., and Mataix, J. (2006). Fatty acid composition of nuts-implications for cardiovascular health. Brit. J. Nutr. 96, S29-S35.

Ruzin, S. E. (1999). Plant Microtechnique and Microscopy. New York, NY: Oxford University Press.

Salimi, M., Majd, A., Sepahdar, Z., Azadmannesh, K., Irian, S., Ardestaniyan, M. H., et al. (2012). Cytotoxicity effects of various Juglans regia (walnut) leaf extracts in human cancer cell lines. Pharm. Biol. 50, 1416-1422. doi: 10.3109/13880209. 2012.682118

Sharma, P., Ravikumarg, G., Kalaiselvi, M., Gomathi, D., and Uma, C. (2013). In vitro antibacterial and free radical scavenging activity of green hull of Juglans regia. J. Pharm. Anal. 3, 298-302. doi: 10.1016/j.jpha.2013.01.006
Stahl, P., Mirom, Y. L., Stern, R. A., and Martin, G. (2019). Comparing 'Iriet' and 'Ettinger' avocado cultivars as pollinators of 'Hass' using SNPs for paternal identification. Sci. Hortic. 248, 50-57. doi: 10.1016/j.scienta.2018.12.003

Teichert, H., Dotterl, S., and Gottsberger, G. (2011). Heterodichogamy and nitidulid beetle pollination in Anaxagorea prinoides, an early divergent Annonaceae. Plant Syst. Evol. 291, 25-33. doi: 10.1007/s00606-010-0367-1

Vinson, J. A., and Cai, Y. (2012). Nuts, especially walnuts, have both antioxidant quantity and efficacy and exhibit significant potential health benefits. Food Funct. 3, 134-140. doi: 10.1039/c2fo10152a

Wang, H., Pei, D., Gu, R., and Wang, B. (2008). Genetic diversity and structure of walnut populations in central and southwestern China revealed by microsatellite markers.J. Am. Soc. Hortic. Sci. 133, 197-203. doi: 10.21273/jashs. 133.2.197

Wang, R. J., Shi, W., Xia, Y. J., Tu, M. W. L. J., Zhang, L. J., and Wang, Y. M. (2015). Antitumor effects and immune regulation activities of a purifed polysaccharide extracted from Juglan regia. Int. J. Biol. Macromol. 72, 771-775. doi: 10.1016/j. ijbiomac.2014.09.026

Wang, X. M., Zhang, P., Du, Q. G., He, H. X., Zhao, L., Ren, Y., et al. (2012). Heterodichogamy in kingdonia (Circaeasteraceae, Ranunculales). Ann. Bot. 109, 1125-1132. doi: 10.1093/aob/mcs041

Xu, H. L., Yu, X. F., Qu, S. C., and Sui, D. Y. (2013). Juglone, isolated from Juglans mandshurica maxim, induces apoptosis via down-regulation of AR expression in human prostate cancer LNCaP cells. Bioorg. Med. Chem. Lett. 23, 3631-3634. doi: 10.1016/j.bmcl.2013.04.007

Ye, Z. M., Jin, X. F., Yang, J., Qing-Feng Wang, Q. F., and Yang, C. F. (2019). Accurate position exchange of stamen and stigma by movement in opposite direction resolves the herkogamy dilemma in a protandrous plant, Ajuga decumbens (Labiatae). AoB Plants 2019:1z052.

Zhang, Y. W., Lin, H., Bao, Y. L., Wua, Y., Yu, C. L., Huang, Y. X., et al. (2012). A new triterpenoid and other constituents from the stem bark of Juglans mandshurica. Biochem. Syst. Ecol. 44, 136-140. doi: 10.1016/j.bse.2012. 04.015

Zhao, M. H., Jiang, Z. T., Liu, T., and Li, R. (2014). Flavonoids in Juglans regia L. leaves and evaluation of in vitro antioxidant activity via intracellular and chemical methods. Sci. World J. 2014:303878.

Zhao, P., and Woeste, K. (2011). DNA markers identify hybrids between butternut (Juglans cinerea L.) and Japanese walnut (Juglan sailantifolia Carr.). Tree Genet. Genomes 7, 511-533. doi: 10.1007/s11295-010-0352-4

Conflict of Interest: The authors declare that the research was conducted in the absence of any commercial or financial relationships that could be construed as a potential conflict of interest.

Copyright (c) 2021 Zhang, Guo, Lu, Sun, Liu, Zhou and Deng. This is an open-access article distributed under the terms of the Creative Commons Attribution License (CC BY). The use, distribution or reproduction in other forums is permitted, provided the original author(s) and the copyright owner(s) are credited and that the original publication in this journal is cited, in accordance with accepted academic practice. No use, distribution or reproduction is permitted which does not comply with these terms. 